\title{
Clostridium difficile Toxin Positive
}

National Cancer Institute

\section{Source}

National Cancer Institute. Clostridium difficile Toxin Positive. NCI Thesaurus. Code C150487.

An indication that Clostridium difficile toxin was detected in a sample. 